\title{
Metachronous isolated breast metastasis from pulmonary adenocarcinoma with micropapillary component causing diagnostic challenges
}

\author{
Young Ju Jeong ${ }^{1}$, Jin Gu Bong ${ }^{1}$, Hoon Kyu Oh², Sung Hwan Park', Sung Min Kang ${ }^{3}$ and Sung Hwa Bae ${ }^{4 *}$
}

\begin{abstract}
Background: Breast metastasis from extramammary malignancy is uncommon and often presents diagnostic challenges. Herein, we report a case of a patient with metachronous isolated breast metastasis from pulmonary adenocarcinoma with micropapillary component.

Case presentation: A 47-year-old woman presented with left breast nodule detected on a screening breast ultrasonography. She had surgery for pulmonary adenocarcinoma 3 years ago, and was disease-free state in the follow up studies. The patient was diagnosed with invasive micropapillary carcinoma of the breast by core needle biopsy. She underwent left breast lumpectomy and sentinel lymph node biopsy, and the histologic findings revealed micropapillary carcinoma. Based on the immunohistochemical study, the final diagnosis was solitary breast metastasis from pulmonary adenocarcinoma with micropapillary component.

Conclusions: The diagnosis of metastasis to the breast from extramammary malignancies is difficult but important for proper management and prediction of prognosis. A careful clinical history with a thorough clinical examination is needed to make the correct diagnosis.
\end{abstract}

Keywords: Breast metastasis, Pulmonary adenocarcinoma, Micropapillary component, Lung cancer

\section{Background}

Metastases to the breast from extramammary malignancy are relatively rare though breast cancer is the most common malignancy in women [1]. Most malignancies seen in the breast are primary carcinomas [2] and the incidence of metastatic disease to the breast is $0.2-6.6 \%$ of all malignant breast tumors [3-8]. The primary malignancies most commonly metastasizing to the breast are leukemia, lymphoma, malignant melanoma and carcinomas from the lung, genitourinary or gastrointestinal tract [9-11]. These metastatic tumors can morphologically simulate breast cancer and lead to misclassification [11], which causes clinical problems because the treatment and prognosis of each tumor differs significantly.

Although lung cancer is one of most common cancer worldwide, there have been only a few published cases of pulmonary carcinoma metastasizing to the breast,

\footnotetext{
*Correspondence: sunghwa@cu.ac.kr

${ }^{4}$ Department of Internal Medicine, Catholic University of Daegu School of Medicine, (705-718) 33, Duryugongwon-ro 17-gil, Nam-gu, Daegu, Korea Full list of author information is available at the end of the article
}

particularly with micropapillary component [12-14]. Invasive micropapillary carcinomas have been described in several organs including urinary bladder, lung, major salivary glands, ovary and breast [15]. Adenocarcinoma with micropapillary component is a morphologic variant of carcinoma and usually recognized as a poor prognostic predictors [15]. We report a case of metachronous isolated breast metastasis from pulmonary adenocarcinoma with micropapillary component which was initially favored to be primary breast cancer. The institutional review board at Daegu Catholic University Hospital granted an exemption from requiring ethics approval for this study.

\section{Case presentation}

A 47-year-old Korean woman presented to the Daegu Catholic University Hospital in Korea with a nodule revealed by screening breast ultrasonography in her left breast. On the physical examination, there was no palpable mass or nipple discharge in both breasts. There was no clinical evidence of regional lymphadenopathy. She had no family history of breast or ovarian cancers. She 
was a non-smoker but had left upper lobectomy of lung because of a pulmonary adenocarcinoma 3 years ago. The pathologic diagnosis was $3.5 \mathrm{~cm}$-sized adenocarcinoma with micropapillary component, and the pathologic stage of lung cancer was T2aN0M0, stage IB.

Mammography revealed only a focal asymmetry in left upper breast and benign calcifications in both breasts (Figure 1A). Ultrasonography revealed two irregular shaped and microlobulated hypoechoic small masses in left upper breast, which was categorized according to Breast Imaging Report and Data System (BI-RADS) as BI-RADS 4C (Figure 1B). The patient underwent ultrasound-guided core needle biopsy. Initial histologic findings revealed proliferation of micropapillae of anaplastic cells in the clear spaces which were consistent with invasive micropapillary carcinoma of the breast (Figure 2). Magnetic resonance imaging of the breast showed no significantly enhancing lesion in both breast. Chest computed tomography (CT) revealed probable benign sub-pleural nodule in right lower lobe but no tumor recurrence or nodal metastasis of lung cancer. On a position emission tomography-CT image there was no evidence of tumor recurrence of lung cancer or distant metastasis.

Clinically, primary breast cancer was suspected, and the patient underwent lumpectomy and sentinel lymph node biopsy using radio-isotope and indigocarmine dye. Gross examination of the specimen revealed an irregular shaped whitish fibronodular lesion, measuring $1.3 \times 1 \mathrm{~cm}$ in size (Figure 3A). The specimen was fixed in 10\% formalin, and paraffin sections were prepared. Hematoxylin and eosin (H\&E)-stained paraffin sections of the lumpectomy specimen revealed extensive micropapillary components (Figure 3B). Microscopic examination of the sections from the specimen showed small clusters of cells within clear stromal spaces resembling dilated vascular channels (Figure 3C) with a desmoplastic reaction. There were no ductal components and carcinoma in situ lesions. There were lymphovascular invasion and some microscopic multiple tumor foci, but resection margins were free from

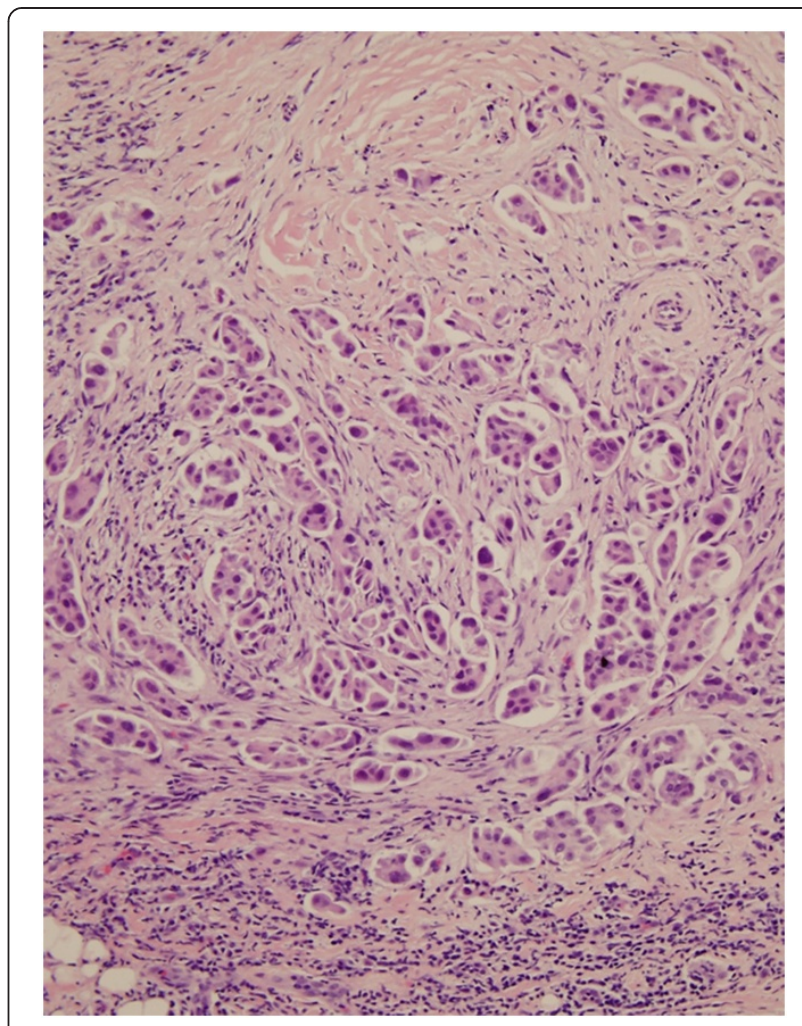

Figure $\mathbf{2}$ Core needle biopsy of left breast tumor. Microscopic findings of the specimen showed proliferation of micropapillae of anaplastic cells in the clear spaces which were consistent with invasive micropapillary carcinoma of the breast (H\&E stain, $\times 400$ ).

tumor. The tumor cells showed triple negative immunoreactivity for estrogen receptor (ER), progesterone receptor (PR) and HER2/neu. The immunohistochemical staining for gross cystic disease fluid protein-15 (GCDFP-15) (Figure 4A) and anaplastic lymphoma kinase (ALK) was negative, but, that for thyroid transcription factor-1 (TTF-1), cytokeratin-7 (CK-7) and Napsin A was positive (Figure 4B-4D). There was no axillary lymph node metastasis. Based on the histology and the immunohistochemical staining patterns, this breast tumor

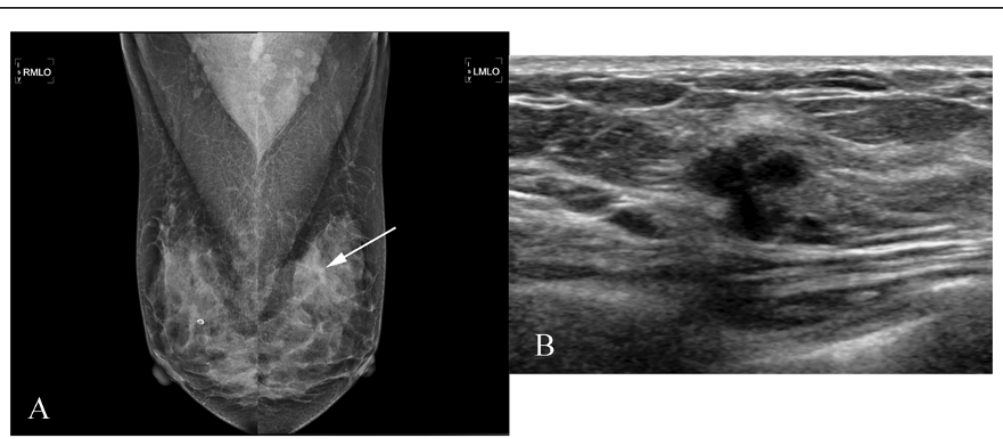

Figure 1 Radiologic findings of the left breast. (A) Mammography showing a focal asymmetry in left upper breast and benign calcifications in both breasts (B) Ultrasonography showing irregular shaped and microlobulated hypoechoic small mass in left upper breast. 


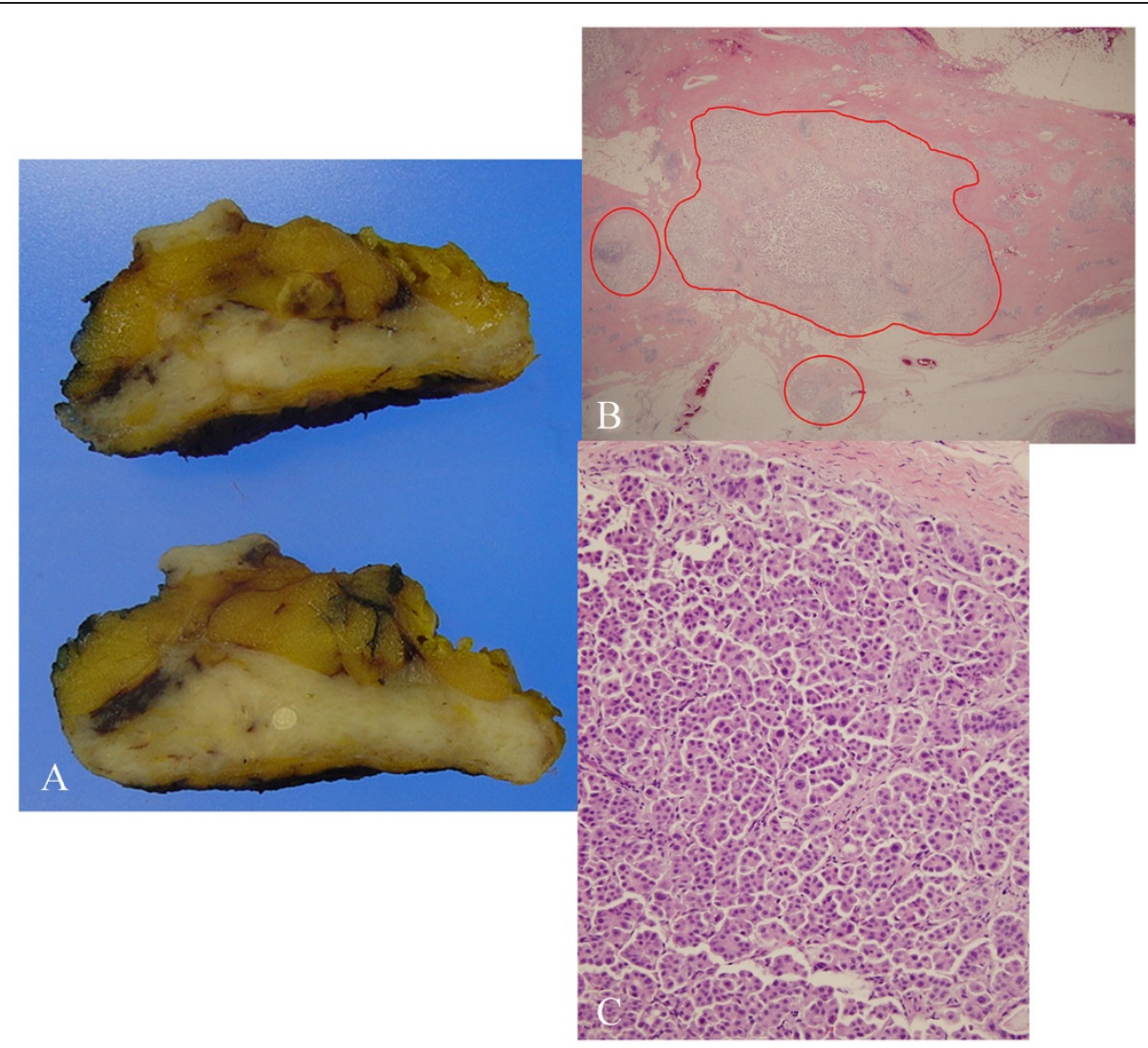

Figure 3 Histologic findings of the left breast tumor after lumpectomy. (A) Gross findings of the specimen showed an irregular shaped whitish fibronodular lesion. (B) Hematoxylin and eosin (H\&E)-stained paraffin sections of the lumpectomy specimen revealed extensive micropapillary components (H\&E stain, $\times 40$ ). (C) Microscopic findings of the specimen showed small clusters of cells within clear stromal spaces resembling dilated vascular channels with a desmoplastic reaction (H\&E stain, $\times 400)$.

was supposed to be a metastatic adenocarcinoma from pulmonary malignancy.

We reviewed the histopathologic findings of the lung cancer removed 3 years ago and compared them with the findings of the breast tumor. H\&E-stained paraffin sections of the lung cancer revealed diffuse infiltration of malignant epithelioid cells showing solid and micropapillary patterns, which resemble the findings of the breast tumor. Also, the lung cancer had the same immunoprofiles as the breast tumor.

We analyzed the mutation of EGFR gene in the breast tumor and the original pulmonary adenocarcinoma specimen. Once informed consent had been obtained, genomic DNA was extracted from paraffin-embedded tumor specimens using QIAamp DNA FFPE Tissue kit (Qiagen, Hilden, Germany) following the manufacturer's instructions. Polymerase chain reaction and mutational analyses of the genes were performed. Exon 18, 19, 20 and 21 of the EGFR gene were analyzed by direct sequencing. DNA sequencing was performed on the pretreated PCR product using an automated direct sequence analyzer (ABI PRISM 3100 Genetic Analyzer; Applied Biosystems, Foster City,
CA, USA). The mutationl analysis revealed same heterozygote mutation in both of the specimens. There was a 9-bp deletion in exon 19, namely, c.2239_2247del9, which resulted in a deletion of three amino acids, namely p.L747_E749del (Figure 5).

From the above results, the patient was diagnosed solitary breast metastasis from pulmonary adenocarcinoma with micropapillary component. Since the mutation test for EGFR was positive, the patient has been taking Gefitinib, being disease-free at 23 month after the diagnosis of the breast metastasis.

\section{Conclusions}

The breast is an unusual site for metastasis from extramammary tumors and metastatic cancer is an unexpected diagnosis in a woman presenting with a breast mass $[16,17]$. The distinction between breast metastasis from extramammary malignancy and primary breast cancer is important for patient management [11]. Some authors have described clinical and histological characteristics of breast metastasis from extramammary malignancies $[5,8,11,18]$. The most common symptoms are 

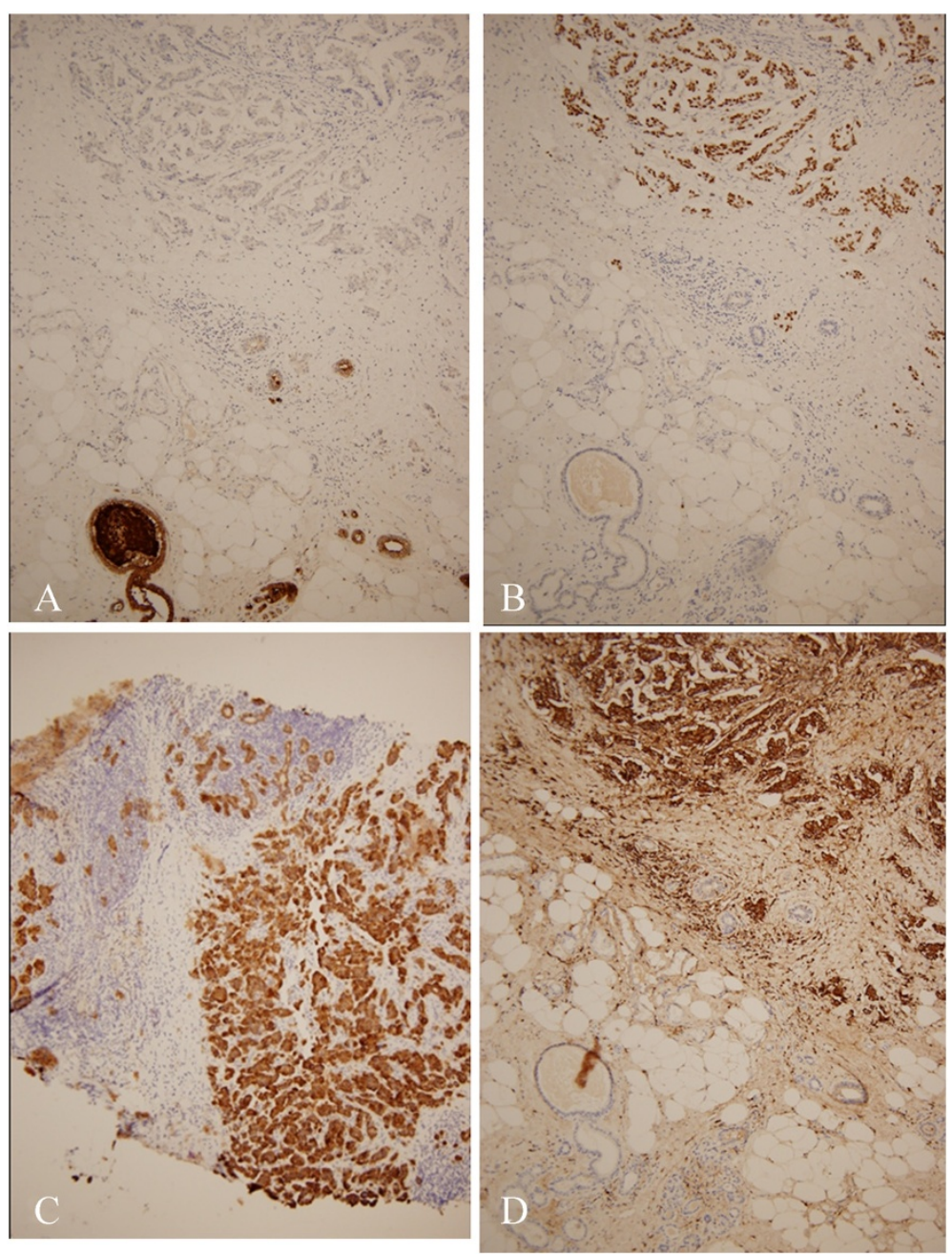

Figure 4 Immunohistochemical staining of the left breast tumor after lumpectomy. (A) GCDFP-15 stain was negative in malignant cells (×400). (B) TTF-1 stain reveals nuclear positivity $(\times 400)$. (C) CK-7 stain was positive in malignant cells ( $\times 400)$. (D) Napsin A stain was positive in malignant cells $(\times 400)$.

solitary discrete lesions in the breast [5,11], while in one study, most patients presented with a history of locoregional and wide spread metastases of extramammary neoplasms [18]. The most common mammographic appearance is of a round mass with well-defined or slightly irregular margins $[11,18]$. In our patient, mammography revealed only a focal asymmetry in left upper and ultrasonography revealed two irregular shaped and microlobulated hypoechoic small masses in left upper breast categorized according to BI-RADS 4C. Histological features of metastases to the breast include atypical histologic features for a primary breast carcinoma, a well-circumscribed tumor with multiple satellite foci, the absence of an intraductal component, and the presence of many lymphatic emboli [4]. However, pathologic diagnosis of breast metastases is difficult, because many extramammary malignancies lack specific histological features and sometimes the features are similar to those of primary breast cancer, particularly with extensive micropapillary patterns $[12,13]$.

Clinical history, radiologic findings and histologic features are helpful in the evaluation of metastatic lesions in the breast. In a review of the ultrasonographic appearances of breast metastases from extramammary malignancies, there are several typical features of breast metastases [19]. Typical ultrasound features of hematogenous metastases include single or multiple, round to oval shaped, well-circumscribed hypoechoic masses without spiculations, calcifications, or architectural distortion [19]. However, lesions show variable radiologic features in some cases and a possibility of a metastasis should be suspected for a breast tumor in a patient with a history of cancer, even if clinically or radiologically benign [20]. Most of primary breast carcinomas originate in the ducts or lobules of the breast and the presence of an in situ (intraductal) component is the only absolute proof of the primary 


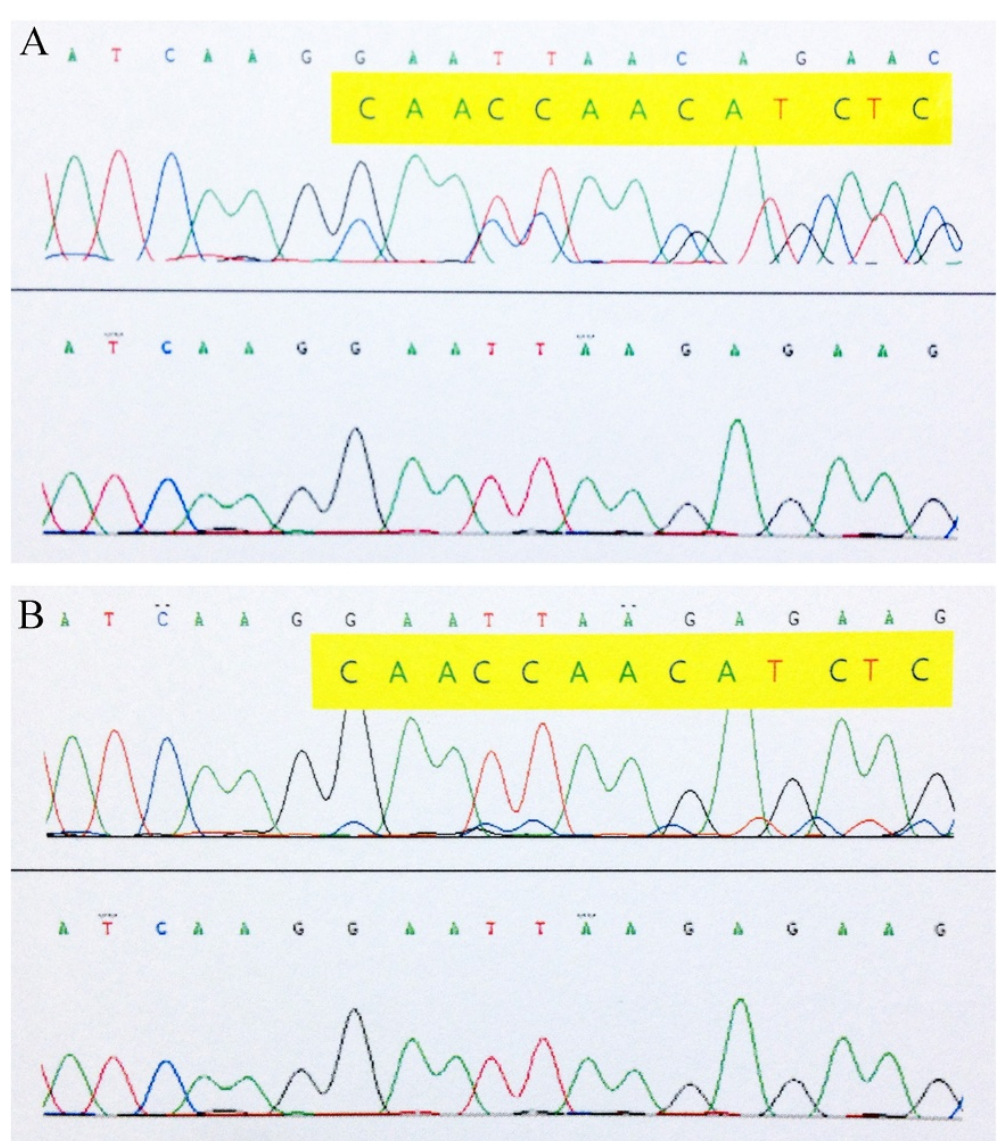

Figure 5 Sequencing results of the heterozygote mutations c.2239_2247del9 (p.L747_E749del) of EGFR gene in breast tumor specimen (A) and lung adencarcinoma specimen (B).

breast carcinoma [21]. After all, whenever a wellcircumscribed tumor is identified in the breast showing lack of in situ components, the possibility of metastatic cancer should be considered and excluded [21], especially in high grade tumors without an in situ component. Also, ER and PR are highly specific markers for breast cancer [11] and ER/PR negative breast tumor without an in situ component is the most common clue for suspicion of metastatic tumor in the breast.

Immunohistochemical studies are necessary for pathologic diagnosis if no primary tumor was known and the clues are subtle to show specific histological features $[4,11]$. An immunohistochemical analysis using a panel of antibodies may be useful to discriminate a primary mammary tumor from an extramammary malignancy because specificity or sensitivity of specific markers is not always 100\% [11]. The combination CK7 and CK20 is useful in categorizing carcinomas [11,22]. The most of breast carcinomas are CK7+ and CK20-, and a CK20+ or CK7pattern would make breast origin less likely [22]. GCDFP15 is also highly specific marker for breast cancer [11]. TTF-1 is a very useful marker in distinguishing pulmonary adenocarcinomas from other primary carcinomas. TTF-1 is expressed in about $75 \%$ of pulmonary adenocarcinomas [11], and no breast carcinomas have been reported to be positive for TTF-1 except rare small cell carcinomas of the breast $[23,24]$. Napsin A is a new marker for pulmonary adenocarcinoma and is known to be more sensitive and specific than TTF-1 in the differential diagnosis of primary pulmonary carcinoma [25]. In our case, the tumor cells showed negative immunoreactivity for ER, PR, HER2/neu and GCDFP-15, and positive for TTF-1, CK-7 and Napsin A.

In a systematic review of the literature, 43 independent case reports were identified for primary lung cancer metastasis to the breast [26]. Of these 43 case reports, only 3 case reports revealed metastasis to the breast from pulmonary adenocarcinoma with a micropapillary component (Table 1). These 3 previous reports [12-14] have described synchronous lung cancer with breast metastasis and demonstrated similar histologic features of breast biopsy including adenocarcinoma with micropapillary component, lymphovascular invasion (lymphatic tumor emboli) and desmoplastic reaction such as dense fibrohyalinized stroma. Maounis et al. [13] and Sanguinetti et al. [14] and also described multiple psammoma bodies 


\begin{tabular}{|c|c|c|c|c|c|c|c|c|c|c|}
\hline Authors, year & Age/Sex & $\begin{array}{c}\text { Chief } \\
\text { complaint }\end{array}$ & $\begin{array}{l}\text { Method of detection } \\
\text { for breast tumor }\end{array}$ & $\begin{array}{c}\text { Breast } \\
\text { tumor size }\end{array}$ & Metachronous & $\begin{array}{l}\text { Initial stage } \\
\text { of lung cancer }\end{array}$ & Management & $\begin{array}{l}\text { Chemotherapy } \\
\text { regimen }\end{array}$ & Survival & Follow-up \\
\hline Ko K, et al., 2012 [12] & $47 / F$ & $\begin{array}{l}\text { Chest pain } \\
\text { with dyspnea }\end{array}$ & Palpable mass on P/Ex. & $1 \mathrm{~cm}$ in diameter & No & IV & Chemotherapy & $\begin{array}{l}\text { Cisplatin/Irinotecan } \\
\text { followed by erotinib }\end{array}$ & Alive & $8 \mathrm{mo}$ \\
\hline $\begin{array}{l}\text { Maounis N, et al., } \\
2010 \text { [13] }\end{array}$ & $73 / F$ & $\begin{array}{l}\text { Dyspnea with } \\
\text { dry cough }\end{array}$ & Palpable mass on P/Ex & Not available & No & IV & Chemotherapy & $\begin{array}{c}\text { Cisplatin/docetaxel/ } \\
\text { bevacizumab }\end{array}$ & Dead & $6 \mathrm{mo}$ \\
\hline $\begin{array}{c}\text { Sanguinetti } A \text {, et al., } \\
2013 \text { [14] }\end{array}$ & $43 / F$ & $\begin{array}{l}\text { Dyspnea with } \\
\text { dry cough }\end{array}$ & Palpable mass on P/Ex & Not available & No & IV & $\begin{array}{l}\text { Simple mastectomy }+ \\
\text { Chemotherapy }\end{array}$ & $\begin{array}{c}\text { Cisplatin/docetaxel/ } \\
\text { bevacizumab }\end{array}$ & Dead & $8 \mathrm{mo}$ \\
\hline This report & $47 / F$ & $\begin{array}{l}\text { Breast nodule on } \\
\text { screening exam }\end{array}$ & Ultrasonography & $1.3 \mathrm{~cm} \times 1 \mathrm{~cm}$ & Yes & $\mathrm{IB}$ & $\begin{array}{l}\text { Lumpectomy + } \\
\text { Chemotherapy }\end{array}$ & Gefitinib & Alive & $23 \mathrm{mo}$ \\
\hline
\end{tabular}

$\mathrm{F}$, female; $\mathrm{P} / \mathrm{Ex}$, physical examination. 
in tumor. In our case, adenocarcinoma with micropapillary component, desmoplastic reaction and lymphovascular invasion were identified, but psammoma body was not observed. To the best of our knowledge this is the first report of metachronous breast metastasis from pulmonary adenocarcinoma with micropapillary component.

It has been documented that breast metastasis from extramammary malignancy has a poor prognosis because most patients have been reported as widely disseminated disease and die within a year of diagnosis $[10,11]$. Specifically, synchronously-presenting lung cancer metastasizing to the breast, namely stage IV lung cancer has carried a very poor prognosis [26]. For patients presenting synchronous lung cancer with breast metastasis, removal of the breast lesion offers no patient benefit [26]. However, removal of the breast lesion could be a useful treatment option for patients with metachronously-presenting lung cancer metastasizing to the breast only, although it has not been established yet whether surgical treatment will affect the prognosis or not. In our case, the patient had only metastasis to the breast and was treated with surgery and anti-EGFR (Gefitinib) treatment. She has been survived with disease free for 23 months following the diagnosis of the breast metastasis.

Micropapillary component is generally thought to have prognostic significance and is associated with a manifestation of aggressive behavior such as lymph node metastases and distant metastases [27,28]. In 3 previous reports [12-14] of synchronously-presenting breast metastasis from pulmonary adenocarcinoma with a micropapillary component, 2 patients died 6 months and 8 months following diagnosis, respectively $[13,14]$, and a patient were alive 8 months after the initial diagnosis of lung cancer [12], although all patients have received systemic chemotherapy. Our patient is currently alive without additional metastasis 23 months after the diagnosis of the breast metastasis, but long-term follow-up is needed.

Here, we report a rare case of metachronous isolated metastasis to the breast from a pulmonary adenocarcinoma with micropapillary component. The distinction between breast metastasis from pulnomary adenocarcinoma with micropapillary component and primary breast micropapillary carcinoma may cause diagnostic challenges. An immunohistochemical analysis is useful for accurate diagnosis. Furthermore, although it is rare, the possibility of metastatic disease to the breast should be considered before making the diagnosis of primary breast cancer, particularly with micropapillary component.

\section{Consent}

Written informed consent was obtained from the patient for publication of this case report and accompanying images. A copy of the written consent is available for review by the Editor of this journal.

\section{Competing interests}

The authors declare that they have no competing interests.

\section{Authors' contributions}

YJJ participated in design of manuscript and provide medical writing and drafted the manuscript. JGB and SHP participated in design of manuscript. SMK participated in data analysis. HKO carried out histopathologic examination and immunohistochemical study. SHB participated in design of manuscript and coordination and helped to draft the manuscript. All authors read and approved the final manuscript.

\section{Acknowledgements}

The authors wish to thank Sung-Hee Mun (Department of Radiology, Catholic University of Daegu School of Medicine) for her technical support and interpretation of data.

\section{Author details}

'Department of Surgery, Catholic University of Daegu School of Medicine, 33, Duryugongwon-ro 17-gil, Nam-gu, Daegu, Korea. ${ }^{2}$ Department of Pathology, Catholic University of Daegu School of Medicine, 33, Duryugongwon-ro 17-gil, Nam-gu, Daegu, Korea. ${ }^{3}$ Department of Nuclear medicine, Catholic University of Daegu School of Medicine, 33,

Duryugongwon-ro 17-gil, Nam-gu, Daegu, Korea. ${ }^{4}$ Department of Internal Medicine, Catholic University of Daegu School of Medicine, (705-718) 33, Duryugongwon-ro 17-gil, Nam-gu, Daegu, Korea.

Received: 15 July 2014 Accepted: 26 September 2014 Published: 1 October 2014

\section{References}

1. National Cancer Institute: Probability of Breast Cancer in American Women. [http://www.cancer.gov/cancertopics/factsheet/detection/probability-breastcancer]

2. Rosen PP: The pathological classification of human mammary carcinoma: past, present and future. Ann Clin Lab Sci 1979, 9:144-156.

3. Canda AE, Sevinc Al, Kocdor MA, Canda T, Balci P, Saydam S, Harmancioglu O: Metastatic tumors in the breast: a report of 5 cases and review of the literature. Clin Breast Cancer 2007, 7:638-643.

4. Vergier B, Trojani M, de Mascarel I, Coindre JM, Le Treut A: Metastases to the breast: differential diagnosis from primary breast carcinoma. J Surg Oncol 1991, 48:112-116.

5. Toombs BD, Kalisher L: Metastatic disease to the breast: clinical, pathologic, and radiographic features. Am J Roentgenol 1977, 129:673-676.

6. Vaughan A, Dietz JR, Moley JF, DeBenedetti MK, Aft RL, Gillanders WE, Eberlein TJ, Ritter J, Margenthaler JA: Metastatic disease to the breast: the Washington University experience. World J Surg Oncol 2007, 5:74.

7. Hajdu SI, Urban JA: Cancers metastatic to the breast. Cancer 1972, 29:1691-1696.

8. McCrea ES, Johnston C, Haney PJ: Metastases to the breast. Am J Roentgenol 1983, 141:685-690.

9. Klingen TA, Klaasen $H$, Aas H, Chen Y, Akslen LA: Secondary breast cancer: a 5-year population-based study with review of the literature. APMIS 2009, 117:762-767.

10. Williams SA, Ehlers RA II, Hunt KK, Yi M, Kuerer HM, Singletary SE, Ross MI, Feig BW, Symmans WF, Meric-Bernstam F: Metastases to the breast from nonbreast solid neoplasms: presentation and determinants of survival. Cancer 2007, 110:731-737.

11. Lee $A H$ : The histological diagnosis of metastases to the breast from extramammary malignancies. J Clin Pathol 2007, 60:1333-1341.

12. Ko K, Ro JY, Hong EK, Lee S: Micropapillary lung cancer with breast metastasis simulating primary breast cancer due to architectural distortion on images. Korean J Radio/ 2012, 13:249-253.

13. Maounis N, Chorti M, Legaki S, Ellina E, Emmanouilidou A, Demonakou M, Tsiafaki X: Metastasis to the breast from an adenocarcinoma of the lung with extensive micropapillary component: a case report and review of the literature. Diagn Pathol 2010, 5:82.

14. Sanguinetti A, Puma F, Lucchini R, Santoprete S, Cirocchi R, Corsi A, Triola R, Avenia N: Breast metastasis from a pulmonary adenocarcinoma: case report and review of the literature. Oncol lett 2013, 5:328-332.

15. Nassar $\mathrm{H}$ : Carcinomas with micropapillary morphology: clinical significance and current concepts. Adv Anat Pathol 2004, 11:297-303. 
16. Yeh CN, Lin CH, Chen MF: Clinical and ultrasonographic characteristics of breast metastases from extramammary malignancies. Am Surg 2004, 70:287-290

17. Babu KS, Roberts F, Bryden F, McCafferty A, Downer P, Hansell DT, Richard J, Robert M: Metastases to breast from primary lung cancer. J Thorac Oncol 2009, 4:540-542.

18. Lee SK, Kim WW, Kim SH, Hur SM, Kim S, Choi JH, Cho EY, Han SY, Hahn BK, Choe JH, Kim JH, Kim JS, Lee JE, Nam SJ, Yang JH: Characteristics of metastasis in the breast from extrammary malignancies. J Surg Oncol 2010, 101:137-140

19. Mun SH, Ko EY, Han BK, Shin JH, Kim SJ, Cho EY: Breast metastases from extramammary malignancies: typical and atypical ultrasound features. Korean J Radiol 2014, 15:20-28.

20. Alexander HR, Turnbull AD, Rosen PP: Isolated breast metastases from gastrointestinal carcinomas: report of two cases. J Surg Oncol 1989, 42:264-266

21. Moinfar F: Special Types of Breast Carcinomas. In Essentials of Diagnostic Breast Pathology: A Practical Approach. Heidelberg: Springer; 2007:223-239.

22. Tot T: Cytokeratin 20 and 7 as biomarkers: usefulness in discriminating primary from metastatic adenomcarcinoma. Eur J Cancer 2002, 38:758-763.

23. Christie M, Chin-Lenn L, Watts MM, Tsui AE, Buchanan MR: Primary small cell carcinoma of the breast with TTF-1 and neuroendocrine marker expressing carcinoma in situ. Int J Clin Exp Pathol 2010, 3:629-633.

24. Klingen TA, Chen Y, Gundersen MD, Aas H, Westre B, Sauer T: Thyroid transcription factor-1 positive primary breast cancer: a case report with review of the literature. Diagn Pathol 2010, 5:37.

25. Turner BM, Cagle PT, Sainz IM, Fukuoka J, Shen SS, Jagirdar J: Napsin A, a new marker for lung adenocarcinoma, is complementary and more sensitive and specific than thyroid transcription factor 1 in the differential diagnosis of primary pulmonary carcinoma: evaluation of 1674 cases by tissue microarray. Arch Pathol Lab Med 2012, 136:163-171.

26. Mirrielees JA, Kapur JH, Szalkucki LM, Harter JM, Salkowski LR, Strigel RM, Traynor AM, Wilke LG: Metastasis of primary lung carcinoma to the breast: a systematic review of the literature. J Surg Res 2014, 188:419-431.

27. Amin MB, Tamboli P, Merchant SH, Ordóñez NG, Ro J, Ayala AG, Ro JY: Micropapillary component in lung adenocarcinoma: a distinctive histologic feature with possible prognostic significance. Am J Surg Pathol 2002, 26:358-364.

28. Maeda R, Isowa N, Onuma H, Miura H, Harada T, Touge H, Tokuyasu H, Kawasaki Y: Lung adenocarcinomas with micorpapillary components. Gen Thorac Cardiovasc Surg 2009, 57:534-539.

\section{doi:10.1186/1471-2407-14-736}

Cite this article as: Jeong et al:: Metachronous isolated breast metastasis from pulmonary adenocarcinoma with micropapillary component causing diagnostic challenges. BMC Cancer 2014 14:736.

\section{Submit your next manuscript to BioMed Central and take full advantage of:}

- Convenient online submission

- Thorough peer review

- No space constraints or color figure charges

- Immediate publication on acceptance

- Inclusion in PubMed, CAS, Scopus and Google Scholar

- Research which is freely available for redistribution

Submit your manuscript at www.biomedcentral.com/submit 